\title{
Evaluating Critical Success Factors for Adoption Decision of e-Learning Facilities in Bangladesh by Using DEMATEL Approach
}

\author{
Gazi Md. Shakhawat Hossain ${ }^{1 *}$, Wei Huang 2 , Md. Abdul Kaium ${ }^{3}$ \\ ${ }^{1}$ Masters of Business Administration (MBA), Management Science and Engineering (MSE), School of \\ Management (SoM), Huazhong University of Science and Technology, Hubei, Wuhan, 430074, P.R. China. \\ 2 Department of Management Science and Information Management, School of Management (SoM), \\ Huazhong University of Science and Technology, Hubei, Wuhan, 430074, P.R. China. \\ ${ }^{3}$ Department of Marketing, University of Barishal, Barishal -8200, Bangladesh. \\ * Corresponding author. Tel.: +8615623459468; email: i201821066@hust.edu.cn \\ Manuscript submitted October 11, 2019; accepted January 17, 2020. \\ doi: 10.17706/ijeeee.2020.10.2.182-204
}

\begin{abstract}
The aim of the study is to evaluating critical success factors for adoption decision of e-Learning facilities in Bangladesh. This research proposed the DEMATEL approach to evaluate possible critical success factors (CSFs) influencing organizational decision to adopt e-learning facilities in the level of primary education system (PES). A quantitative survey method was performed through the structured questionnaire. The questionnaire involved pairwise comparison of elements on a five-point scale ranging from 0 to 4 respectively $(0=$ No influence, $1=$ Low influence, $2=$ Medium influence $3=$ High influence $4=$ Very High influence). The survey questionnaire was distributed to $14(n=14)$ experts of educational department for obtaining their judgment. MATLAB-2019 a, SPSS-23 and MS Excel were used to analyze the data. The result of this study revealed that the expert's member is more concerned about human and technology related dimensions that are substantially higher than those of other dimensions with influence value of prominence and relation $(\mathrm{r} \pm \mathrm{c})$ 0.5602, and 1.5690 respectively. This study proposed an approach for the strategic planning of e-learning facilities within the primary education system based on effective group decision making from the perspective of human, technology, organization, and environmental dimensions' processes. However, the government should allocate enough budget to ensure quality education based on the core dimensions of HTOE model. The authors recommended to the policy makers to incorporate e-learning facilities in the primary education institutes based on the principles of e-learning systems under the access to information (A2I) national project.
\end{abstract}

Key words: Adoption decision, Bangladesh, DEMATEL approach, e-learning.

\section{Introduction}

The use of information and communication technology (ICT) has been playing a vital role in the 21st century due to globalization [1] and the government is being encouraged to adapt use of different technology. GOB [2] has declared the "Vision 2021" in the election manifesto which targets establishment of a resourceful country by 2021 through effective use of ICT- a "Digital Bangladesh". Therefore, the government underscores a changing attitude, positive thinking and innovative ideas WB [3] or the success of "Digital Bangladesh". 
BBI [4] posited that most of the media, government departments and ministries, Bangladesh Electricity Authority, Bangladesh Telecommunication Corporation, Water Supply Corporation, travel agencies, and most financial organizations in Bangladesh use ICT. Digital Bangladesh does not only mean the broad use of computers, perhaps it means the modern philosophy of effective and useful use of technology in terms of implementing the promises in education, health, job placement, poverty reduction etc.

Education is fundamental to the development of Bangladesh and has placed a high priority on it [5]. Highest allocations for education in the national budgets since nineties show that the government has attached topmost priority to human resource development though education. The goal of 'Education for All' is being vigorously pursued in the country. Education in Bangladesh has three major stages primary, secondary and higher educations. According to ministry of education, primary education is a 5-year cycle while secondary education is a 7- year one with three sub-stages: 3 years of junior secondary, 2 years of secondary and 2 years of higher secondary. The entry age for primary is 6 years. Bangladesh Bureau of Statistics clarified that the junior, secondary and higher stages are designed for age groups 11-13, 14-15 and 16-17 years. Compulsory primary education, free education for girls up to class ten, stipends for female students, food-for educational total literacy movement and nationwide integrated education are some of the major programs being the government in the education sector [5].

The education sector of Bangladesh has been suffering from many deficiencies including quality teachers, quality content and quality environment [6]. The significant necessity of study via e-learning is the ability to self-study, responsibility, ability to organize and plan the time, computer literacy at a certain level and availability of technology [7].

The ability to self-study is not fully developed by primary school pupils. O'neill, Singh [8] posited that e-learning describes the principles of effective multimedia learning by using electronic educational technology. According to Dietinger [9] e-learning is identified as one of the emerging areas and has turned out to be important for educational institutions as highlighted by concrete application scenarios. Models of e-learning describe where technology plays a specific role in supporting learning and these can be described at the level of detailed practice in implementing those principles [10]. Models that emphasize the interactions possible in e-learning (learner to instructor, learner to learner, learner to content, learner to context) have been suggested by Garrison [11].

The pupils taught via e-learning have to be supported by their teacher/ leader/parent in primary education [12]. The e-learning education has only a supportive character. It is an optional alternative. Primary schools use e-learning as a supplement or an extension of the traditional "full-time" education. It is suggested to implement the e-learning into primary education in the form of e-learning exercises for strengthening the curriculum [13]. The methods used in primary education should motivate pupils, lead them to the learning activity and to the realization that it is possible to search, discover, create and find suitable ways of solving problems. The primary education requires stimulating and creative environment that motivates the brightest pupils, encourages the less talented pupils, protects and supports the weakest ones [14]. E-Learning can improve the quality of education by:

- providing access to a range of resources and materials which may not otherwise be available or accessible, for example graphics, sound, animation, multimedia;

- providing a student-centered learning environment which can be tailored to meet the learning needs of individual students;

- providing attractive multimedia learning without any tutor and making it easier to amend and update materials.

The implementation of e-learning to education is one of the possibilities for the development of computational literacy at all levels of education [15]. The e-learning has been widely implemented to 
education not only at universities, but also at secondary schools. There are primary schools implementing e-learning as a new and contemporary method of learning as well [16]. The primary e-learning has certain specifics related to primary educational requirements. The requirements on pupils at primary schools are significantly different in comparison with requirements put on students at higher level of education [16]. An analogous situation in the Czech Republic was described by [17]. During full time education, pupil's learning is driven by a teacher or parents. The motivation plays significant role. Only the motivation can "force" pupils to learn, although classmates are a supporting factor, too.

Alstrup and Rootzén [18] realized that learning efficiency can be influenced by the introduction of adaptability to e-learning. The paper also introduces new findings in cognitive computing in learning systems as it describes the implementation of adaptive elements into primary school e-learning. Hubalovsky, Hubalovska [14] deals with in the literature rarely discussed issue of the use of e-learning in primary education (children 6-10 years) and thus it brings new knowledge in the field of learning.

The conviction of authors about e-Learning suitability for primary school teachers is supported by a study [19]. The study states that "the factors which had no statistically significant impact ( $p>.05)$ included the teacher's age, gender, type of school, and prior experience with e-learning. The very same opinion is supported also by a study of [20] which deals with the acceptance of digital learning environment.

Information and Communication Technology (ICT) has changed our lives to many extents through application of computers more specifically education system of a country. In today's information society, the importance of application of computers is only likely to rise. The use of computers in the classroom is not a new issue. In view of the first rate of technological development, authority constantly need to adapt to new technologies for ensuring quality education in the root level (class: 1-5) and refine their skills in order to integrate technology into the classroom. Most of the researcher concentrated on the learning environment context, but fully skip mode of learning (e-Learning) facilities in classroom. For the latter, fewer studies have been conducted to evaluating what factors are crucial on organizational decision to adopting a specific innovative technology. The present research attempts to bridge this gap by empirically evaluating possible critical success factors (CSFs) influencing decision to adopt e-learning facilities in the level of primary education system by applying DEMATEL approach. This paper describes an empirical study that evaluating possible critical success factors (CSFs) influencing organizational authority decision to adopt e-learning facilities in the level of primary education system (PES) of Bangladesh. The single research question that have been raised for this study are:

What are the significant possible critical success factors (CSFs) that influencing organizational authority decision to adopt e-learning facilities in the level of primary education system (PES) based on Human Technology Organization Environment (HTOE) framework?

In order to answer this research questions, the study proposes the development and validation of a theoretical model that considers behavioral, psychosocial and technology-related elements. The results of the research may provide further insight on the technology adoption process that aim to promote the use of multimedia projector in the future teaching practice of their students. In addition, this study proposes the DEMATEL to evaluate and find the importance level of the determined factors for adopt e-learning facilities in the level of primary education system (PES). By using this approach, the interdependencies strength among the adoption factors are tested [21]-[24]. The paper is structured as follows: section 2 presents a review of the literature; section 3 describes the data collection procedure; and the analysis of the data, the results are presented and discussed in section 4; and section 5 provides some of policy guidelines.

\section{Conceptual and Theoretical Framework Development}




\subsection{Factors Influencing Decision to Adopt e-Learning Facilities}

Tornatzky, Fleischer [25] introduced the TOE framework in 1990. It is the organizational level theory that predicts the technology adoption decision, explained by three different contexts. From the TOE perspective, the process by which an organization adopts and implements technological innovations that is influenced by the technological context, the organizational context, and the environmental context [26]. The technology context comprises of the internal and external technologies pertaining to the firm involves and includes both equipment and process. The organizational context involves the characteristics and resources of the firms such as firm size, managerial structure, human resources, the amount of slack resources and linkages among employees. The environmental context includes the structure of the industry, the macroeconomic concept and the regulatory environment. These factors play an important role in facilitating or inhibiting the decision to adopt an innovation in organizations. According to Yusof, [27] human and organizational aspects are essential as much as technical issues in connection to the system effectiveness. Hence, Yusof, [27] provided a comprehensive, specific evaluation view integrating the dimensions into the developed HOT-fit model. Following the work conducted by Yusof, [27]. HOT-fit model would be applied in a flexible way, taking into account different contexts and purposes, and evaluation methods.

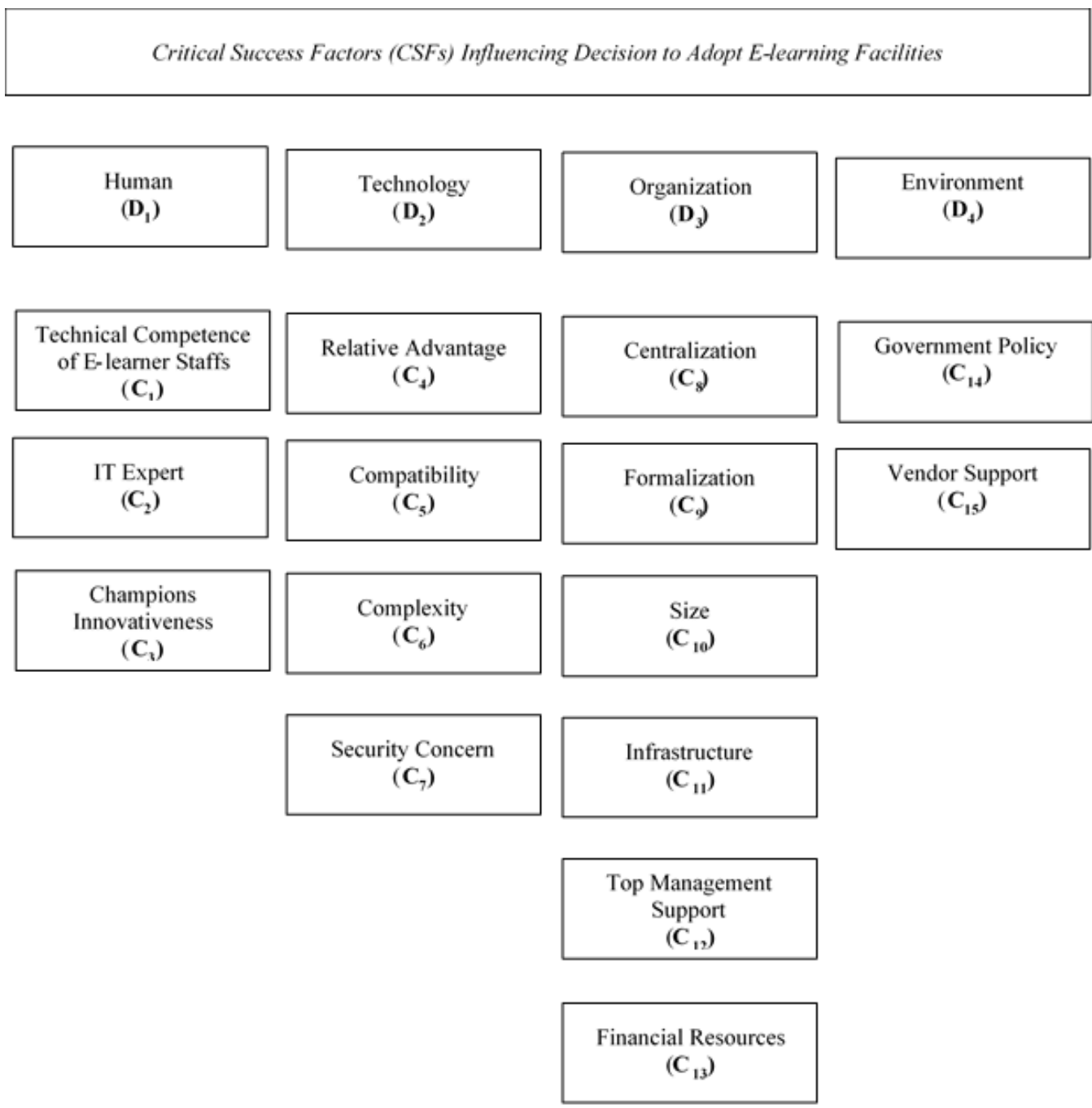

Fig. 1. Critical success factors (CSFs) influencing decision to adopt e-learning facilities.

First, factors under human dimension included technical competence of e-learner staffs Yap [28] IT 
experts Soliman and Janz [29] and champions innovativeness Agarwal and Prasad [30] Second, factors under technology dimension, are relative advantages Tornatzky and Klein [26] compatibility Chang, Hwang [31] complexity M Rogers [32] and security concern Ratnasingham [33].Third, factors under the organization dimension are centralization Grover [34], formalization Zmud [35], size Ahmadi, Rad [36], infrastructure [34], top management support Lian, Yen [37], and financial resources Greenhalgh, Robert [38]. Fourth, factors under the environment dimension are government policy Tornatzky, Fleischer [25] and vendor support Hsiao, Li [39] which has an effect on decision to adopt e-learning facilities in the classroom and effect were shown in Fig. 1

Based on the above statements and aforementioned discussion, both TOE framework and HOT-fit model are deemed suitable in the study at hand that is to apply the integrated developed HTOE Tornatzky and Klein [26] \& Yusof, [27] dimensional model to understand the adoption decision of e-learning facilities in the primary education system. Based on the literature review, theoretical background and previous empirical research findings, this study develops the conceptual research model (see Fig. 2). This model contains the factors pertaining to each context which is to realizing of the adoption process of e-learning system in the classroom. This study attempts to provide an informative guidance model with respect to decision-makers in improving and promoting a better decision in adopting a new technology in the organizational context. The whole developed e-learning adoption decision model, including both dimensions and related latent variables has been presented in Table 1.

Note: C1 - Technical Competence of e-learner staffs, C2 - IT experts, C3 - Champions Innovativeness, C4 Size, C5 - Compatibility, C6 - Complexity, C7 - Security Concern, C8 - Centralization, C9 - Formalization, C10 - Size, C11 - Infrastructure, C12 - Top Management Support, C13 - Financial Resources, C14 - Government Policy, C15 - Vendor Support

Table 1. Proposed Factors Influencing the Decision to Adopt e-Learning Facilities Based HTOE Framework Explanation of variables

\begin{tabular}{|c|c|c|c|}
\hline Dimension & Criteria & Descriptions & Source \\
\hline \multirow[t]{3}{*}{$\begin{array}{l}\text { Human } \\
\left(D_{1}\right)\end{array}$} & $\begin{array}{c}\text { Technical } \\
\text { Competence of } \\
\text { e-learner staffs } \\
\left(\boldsymbol{C}_{\boldsymbol{1}}\right)\end{array}$ & $\begin{array}{l}\text { The staff have sufficient knowledge and the adequate skills to } \\
\text { adopt IT innovation technology, system will undoubtedly posit } \\
\text { more confidence all over the process of adoption. }\end{array}$ & {$[\underline{28}]$} \\
\hline & $\begin{array}{l}\text { IT experts } \\
\left(\boldsymbol{C}_{2}\right)\end{array}$ & $\begin{array}{l}\text { The staff are able to execute their tasks well and demonstrate a } \\
\text { sound understanding of the organization's needs, an ability to be } \\
\text { good consultants and provide world-class support, and an } \\
\text { undertaking to keep up to date with new techniques and } \\
\text { technology that may improve the organization's IS/IT } \\
\text { effectiveness. }\end{array}$ & [29] \\
\hline & $\begin{array}{l}\text { Champions } \\
\text { Innovativeness } \\
\left(\boldsymbol{C}_{3}\right)\end{array}$ & $\begin{array}{l}\text { Actions or behavior by the members of the organization can } \\
\text { directly or indirectly influence organizational effectiveness. }\end{array}$ & {$[\underline{30}]$} \\
\hline \multirow[t]{3}{*}{$\begin{array}{l}\text { Technology } \\
\left(D_{2}\right)\end{array}$} & $\begin{array}{l}\text { Relative Advantages } \\
\qquad\left(\boldsymbol{C}_{4}\right)\end{array}$ & $\begin{array}{l}\text { Relative advantage is the degree to which an innovation is } \\
\text { perceived as better than its precursor. relative advantages will } \\
\text { influence business and force them to adopt new information } \\
\text { technologies }\end{array}$ & {$[\underline{26}]$} \\
\hline & $\begin{array}{l}\text { Compatibility } \\
\left.\text { ( } \boldsymbol{C}_{5}\right)\end{array}$ & $\begin{array}{l}\text { The sub-systems of organization are more compatible with the } \\
\text { existing systems and/or it would be more hopeful and more } \\
\text { feasible to adopt them. }\end{array}$ & [31] \\
\hline & $\begin{array}{l}\text { Complexity } \\
\left(\boldsymbol{C}_{6}\right)\end{array}$ & $\begin{array}{l}\text { Complexity refers to the degree to which an innovation is } \\
\text { perceived as difficult to use that the perceived complexity of an } \\
\text { innovation leads to } \\
\text { resistance due to lack of skills and knowledge. }\end{array}$ & {$[\underline{40}]$} \\
\hline
\end{tabular}




\begin{tabular}{|c|c|c|c|}
\hline & $\begin{array}{l}\text { Security Concern } \\
\qquad\left(\boldsymbol{C}_{7}\right)\end{array}$ & $\begin{array}{l}\text { Considering the IT innovation adoption, the reliability of } \\
\text { network and information security are key factors. }\end{array}$ & [33] \\
\hline \multirow{6}{*}{$\begin{array}{l}\text { Organization } \\
\qquad\left(D_{3}\right)\end{array}$} & Centralization $\left(\boldsymbol{C}_{\boldsymbol{8}}\right)$ & $\begin{array}{l}\text { Centralization or the concentration of decision-making activity, } \\
\text { frequently has been referred to have a negative relationship on } \\
\text { adoption of organizational innovation. }\end{array}$ & [34] \\
\hline & $\begin{array}{l}\text { Formalization } \\
\qquad\left(C_{9}\right)\end{array}$ & $\begin{array}{l}\text { Similarly, formalization, or clear work and procedure } \\
\text { definition have been found as a negative association with } \\
\text { initiation/adoption. }\end{array}$ & [35] \\
\hline & $\begin{array}{l}\text { Size } \\
\left(C_{10}\right)\end{array}$ & $\begin{array}{l}\text { The large and tertiary organization obtain more resources to } \\
\text { change the business strategy, which lead to have more tendency } \\
\text { in adopting the IS/IT innovation. }\end{array}$ & [36] \\
\hline & $\begin{array}{l}\text { Infrastructure } \\
\qquad\left(C_{11}\right)\end{array}$ & $\begin{array}{l}\text { IS infrastructure is made up of various tangible resources } \\
\text { which includes, infrastructure components such as hardware and } \\
\text { software. IS infrastructure describing a firms' ubiquitous state-of } \\
\text { the art telecommunication and database resources }\end{array}$ & [34] \\
\hline & $\begin{array}{l}\text { Top Management } \\
\text { Support } \\
\left(\boldsymbol{C}_{12}\right)\end{array}$ & $\begin{array}{l}\text { Top manager 's support refers to whether or not the top } \\
\text { managers understand the nature and functions of innovation and } \\
\text { therefore fully support the development of it. }\end{array}$ & [37] \\
\hline & $\begin{array}{l}\text { Financial Resources } \\
\qquad\left(\boldsymbol{C}_{13}\right)\end{array}$ & $\begin{array}{l}\text { Financial readiness refers to the financial resources available } \\
\text { to pay for installation costs, implementation of any subsequent } \\
\text { enhancements, and ongoing expenses during usage. }\end{array}$ & [요 \\
\hline \multirow[t]{2}{*}{$\begin{array}{l}\text { Environment } \\
\quad\left(D_{4}\right)\end{array}$} & $\begin{array}{l}\text { Government Policy } \\
\qquad\left(\boldsymbol{C}_{14}\right)\end{array}$ & $\begin{array}{l}\text { Government policy is an imperative factor in the aspect of } \\
\text { environment and pertain to environmental context influence } \\
\text { organizational adoption of technological innovation. }\end{array}$ & [25] \\
\hline & $\begin{array}{l}\text { Vendor Support } \\
\left.\text { ( } \boldsymbol{C}_{\mathbf{1 5}}\right)\end{array}$ & $\begin{array}{l}\text { Vendors can provide various other services such as product } \\
\text { installation, training or big-scaled business consultancy. }\end{array}$ & [39] \\
\hline
\end{tabular}

As we discussed in the previous section, based on previous noteworthy empirical research findings, and theoretical background. Accordingly, in this section we developed a hybrid MCDM model [41]-[47], for the process of e-learning adoption decision. The proposed MCDM model is comprised of two main stages. An overview of the process of hybrid proposed model using DEMATEL is shown in Figure-2. In the first step, the DEMATEL method is use to uncover the relationship among the dimensions (main factors) and variables (sub-factors) and to find interdependency and feedback among them [24], [48], [49]. It should be noted that uncovering the relationship using this approach is very important to find the weight of the main factors and sub-factors appropriately. Hence to this step, DEMATEL approach is more suitable to apply in decision making as it is more suitable for real world applications [23], [50], [51].

\subsection{DEMATEL Method}

DEMATEL method was originally developed in 1973. Science and Human affairs program of the Battelle Memorial Institute conducted the DEMATEL projects through its Geneva Research Center by Gabus and Fontela [52]. It was initially created to study the world problem structure by analyzing scientific, political and economic problems that are influenced by a different factors and sub-factors. In recent years, the original DEMATEL method has been widely accepted as one of the best tools to solve the cause and effect relationship among the evaluation criteria [22]. In a totally interdependent system, all criteria of the system are mutually related directly or indirectly; and any interface with one of the criteria affects all the others; so, it is difficult to find prioritize for decision making. The aim of the DEMATEL method is to covert the relationship between cause and effect of criteria into an intelligible structural model of the system [43], [49], [53]-[55].

In recent years, this method has become very popular in Japan. It is especially practical and useful for visualizing the structured of the complicated causal relationships with matrix or diagraphs which portray the contextual relationship between the elements of a system. The DEMATEL method has been successfully 
applied in many fields. For example, Chiu, Chen [56] adopted the method to study marketing strategy based on customer behavior related to LCD-TVs. DEMATEL is employed to confirm the influence relationship and level among dimensions and criteria from expert judgment by questionnaire [54], [57]. First, we compute the data from expert questionnaires to gain the total relation matrix to influence map by DEMATEL. A research flow chart along with process of proposed approach is shown in Figure-2, and the definitions of notations used in DEMATEL is presented in Table 2. The procedures of the DEMATEL method and the evaluation process can be summarized as follows:

Table 2. Definitions of Notations Used in DEMATEL Approach

\begin{tabular}{|c|c|c|}
\hline Equation & Notation & Definition \\
\hline \multirow{3}{*}{ (i) } & $Z_{i j}$ & is the average number of average matrix $\mathbf{Z}$; \\
\hline & $m$ & is the number of experts; \\
\hline & $x_{i j}{ }^{k}$ & is the influence score that $\boldsymbol{i}_{\boldsymbol{t} \boldsymbol{h}}$ criterion on $\boldsymbol{j}_{\boldsymbol{t} \boldsymbol{h}}$ criteria of $\boldsymbol{k}_{\boldsymbol{t} \boldsymbol{h}}$ expert; \\
\hline \multirow[t]{2}{*}{ (ii) \& (iii) } & $\boldsymbol{Y}$ & is the largest number of the sum of each $\boldsymbol{i}_{t h}$ Column or $\boldsymbol{j}_{\boldsymbol{t} h}$ row in average matrix; \\
\hline & $\boldsymbol{D}$ & is the normalized initial direct-relation matrix which derived from $\mathrm{Z}^{*} \mathrm{Y}$. \\
\hline \multirow[t]{2}{*}{ (iv) } & $T$ & is the total relation matrix which derived from $D(I-D)^{-1}$ \\
\hline & I & is the identity matrix \\
\hline \multirow[t]{2}{*}{ (v) \& (vi) } & $r_{i}$ & Denotes the row sum of the $\boldsymbol{i}_{\boldsymbol{t} h}$ row of matrix $\boldsymbol{T}$ \\
\hline & $c_{i}$ & Denotes the column sum of the $\boldsymbol{i}_{t h}$ column of matrix $\boldsymbol{T}$. \\
\hline $\mathbf{D}_{1}, \mathbf{D}_{2}, \ldots . \mathbf{D}_{\mathbf{n}}$ & & are the $\boldsymbol{n}_{t h}$ dimensions. \\
\hline $\mathbf{C}_{1}, \mathbf{C}_{2}, \ldots . \mathbf{C}_{\mathrm{n}}$ & & is the $\boldsymbol{n}_{\boldsymbol{t h}}$ criterion (sub-factor or variable) of $\boldsymbol{n}_{\boldsymbol{t} \boldsymbol{h}}$ dimensions \\
\hline
\end{tabular}

Step-1: Gather expert's opinion and producing the average matrix Z (or, calculating the direct relation matrix)

In the first strep, the DEMATEL method is used to uncover the relationship among the dimensions (main factor) and variables (also called sub-factor or criteria under each dimensions) and to find interdependency and feedback among them that affecting the system. This can be done using literature search or expert opinion. In addition, a comparison measuring scale has to be defined which can be used to express the relationship or strength of influence between the dimensions (main factors) or variables (or criteria under each dimensions or sub-factor).

$\begin{array}{cc}\text { Numeral/ Value } & \text { Definition } \\ 0 & \text { No influence } \\ 1 & \text { Low influence } \\ 2 & \text { Medium influence } \\ 3 & \text { High influence } \\ 4 & \text { Very High influence }\end{array}$

Experts are asked to indicate the direct influence degree between criterion $i^{\text {th }}$ and criterion $j^{\text {th }}$ in which they believed that any of the factors influences each other by applying the aforementioned comparison influence. The degree to which the expert perceived factor $i$ effects on factor $j$ is denoted as $X_{i j}$ (using a pairwise comparison scale designated five levels where the score ranging from 0 to 4 respectively). In mathematical notations this means if we have a group of $m$ experts and $n$ factors are used in this step. We get from every expert a $n^{*} n$ answer matrix

$\begin{array}{llll}0 & \mathrm{X}_{12} & \cdots & \mathrm{X}_{1 \mathrm{n}}\end{array}$ 


\begin{tabular}{|c|c|c|c|}
\hline \multirow{3}{*}{$X=$} & $X_{21}$ & 0 & $\ldots$ \\
\hline & $\ldots$ & $\ldots$ & $\ldots$ \\
\hline & $\mathrm{X}_{\mathrm{n} 1}$ & $\mathrm{X}_{\mathrm{n} 2}$ & $\ldots$ \\
\hline
\end{tabular}

$X^{k}=\left[x_{i j}{ }^{k}\right]$ with $1 \leq k \leq m$ where, $k$ is the expert number of participating in evaluation process and $X^{1}, X^{2}$, $X^{3}, \ldots . ., X^{n}$ are the metrics from $m$ experts. The main diagonal elements of each answer matrix are set to zero $(0)$, because self-influence of the factor is not evaluated in DEMATEL. $Z=\left[Z_{i j}\right]_{1 \times 1}$ is constructed by calculating the average influence quantification and aggregate all judgement from $m$ experts, the average matrix. $Z=\left[Z_{i j}\right]$ is shown below:

$$
Z_{i j}=\frac{1}{m} \sum_{j=1}^{m} x_{i j}^{k}
$$

This matrix $\mathrm{Z}$ is also called the direct relation matrix. The initial direct relation matrix is obtained by pairwise comparisons in terms of influences and directions between criteria in which $\mathrm{n}$ denotes number of criteria. This direct relation matrix can also be depicted in an influencing map.

Step-2: Calculate the normalize initial direct-relation matrix D

The second step calculates the normalized direct relation matrix D from the average matrix $\mathrm{Z}$. This is done by dividing each element by the largest row sum of the average matrix as in the original DEMATEL method. Some recent applications of the method also used the largest row or the column sum as the standard for normalization, but this is not followed in the context of this paper. The normalization factor max. $1 \leqslant \mathrm{i} \leqslant \mathrm{n} \quad \sum_{-}(\mathrm{j}=1)^{\wedge} \mathrm{n}$ aij represents the total direct influence in our influence scale of the factor with the most direct influence on other factors. This normalization step is the preparation for the following steps of DEMATEL where indirect influences are calculated and provides an aligned scale for all factors for these calculations. On the basis of the direct relation matrix $\mathrm{Z}$, normalize direct relation matrix $\mathrm{D}$ can be obtained through formulas (ii) and (iii). So scalar $Y$ is computed with:

$$
Y=1 / \max 1 \leq i \leq n \sum_{j=1}^{n} \quad \text { aij }
$$

where, $\mathrm{i}, \mathrm{j}=1,2, \ldots \ldots . ., \mathrm{n}$

And, then is used to compute the normalized direct relation matrix $\boldsymbol{D}$ with

$$
D=Z^{*} Y
$$

\section{Step-3: Calculate the total relation matrix $\mathrm{T}$}

Once the normalized direct-relation matrix $D$ has been obtained, the total relation matrix $T$ can be derived by using formula (iv) I which $I$ is an $n^{*} n$ the identity matrix. The elements of $t_{i j}$ represents the indirect effects that factor $i$ had on factor $j$, then matrix $T$ reflects the total relationship between each pair of system factors. The experts have estimated the directs effect only. It is assumed that the indirect effects of the influence factors (factor $a$ influences factor $b$ and factor $b$ influences factor $c$, so factor $a$ indirectly also influences factor $c$ ) is lower than the direct effects with increasing indirections the indirect influence matrix:

$$
\begin{aligned}
& \boldsymbol{T}=\lim _{\mathrm{m} \rightarrow \infty}\left(\mathrm{D}+\mathrm{D}^{2}+\ldots \ldots \ldots \ldots+\mathrm{D}^{\mathrm{m}}\right) \\
& =\sum_{m=1}^{\infty} \boldsymbol{D}^{\boldsymbol{i}} \quad \text { where, } \quad \sum_{m=1}^{\infty} \quad \boldsymbol{D}^{\boldsymbol{i}}=\boldsymbol{D}^{\mathbf{1}}+\boldsymbol{D}^{\mathbf{2}}+\ldots \ldots \ldots \ldots+\boldsymbol{D}^{\boldsymbol{m}}
\end{aligned}
$$




$$
\begin{aligned}
& =D\left(I+D^{1}+D^{2}+\ldots \ldots \ldots \ldots+D^{m-1}\right) \\
& =D(I-D)^{-1}(I-D)\left(I+D^{1}+D^{2}+\ldots \ldots \ldots \ldots+D^{m-1}\right) \\
& =D(I-D)^{-1}\left(I-D^{m}\right) \\
& T=D(I-D)^{-1}
\end{aligned}
$$

Step-4: Calculate the sums of rows and columns of matrix $T$

In the total relation matrix $\boldsymbol{T}$, the sum of rows and the sum of the columns are represented by vectors $\boldsymbol{r}$ and $\boldsymbol{c}$ respectively as shown in formula (v) and (vi). Then, the horizontal axis vector $(\mathrm{r}+\mathrm{c}$ ) called "prominence" is formed by adding $\boldsymbol{r}$ to $\boldsymbol{c}$ which indicates the level of importance of the criterion. Similarly, vertical axis $(\boldsymbol{r}-\boldsymbol{c})$ called "relation" is formed by subtracting $\boldsymbol{c}$ from $\boldsymbol{r}$ which may divide criteria into a cause group and an effect group. When (r-c) is positive the criterion belongs to the cause group otherwise it belongs to the effect group.

$$
\begin{aligned}
& r=\left[r_{i}\right] n \times 1=\left(\sum_{j=1}^{n} \quad t_{i j}\right) n x 1, \\
& r=\left[r_{i}\right] n \times 1=\left(\sum_{j=1}^{n} \quad t_{i j}\right) 1 \times n,
\end{aligned}
$$

where, $[\mathbf{C} \boldsymbol{j}]$ ' is denoted as transportation matrix.

Let, $\boldsymbol{r}_{\boldsymbol{i}}$ be the sum of $\boldsymbol{i}^{\text {th }}$ row in matrix $\boldsymbol{T}$. The value of $\boldsymbol{r}_{\boldsymbol{i}}$ indicates the total given both directly and indirectly effects, that factor $\boldsymbol{i}$ has on the other factors.

Let, $\boldsymbol{c}_{\boldsymbol{j}}$ be the sum of $\boldsymbol{i}^{\text {th }}$ column in matrix $\boldsymbol{T}$. The value of $\boldsymbol{c}_{\boldsymbol{j}}$ shows the total received both directly and indirectly effects, that all other factors have on factors $\boldsymbol{j}$.

[If $\boldsymbol{j}=\boldsymbol{I}$, the value of $(\boldsymbol{r} \boldsymbol{i}+\boldsymbol{c i})$ represents the total effects both given and received by factor $\boldsymbol{i}$. In contrast, the value of ( $\boldsymbol{r i} \mathbf{-} \boldsymbol{c i})$ shows the net contribution by factor i on the system.]

Step-5: Set a threshold value $(\alpha)$ and build a cause and effect relationship diagram

The threshold value $(\alpha)$ was computed by the average of the elements in matrix T as computed by Eq. (vii). This calculation aimed to eliminate some minor effects elements in matrix $\mathrm{T}$.

$$
\alpha=\sum_{i=1}^{n} \quad \sum_{j=1}^{n} \quad[t i j] / N
$$

where $\boldsymbol{N}$ is the total number of elements in the matrix $\boldsymbol{T}$

The causal diagram can be derived by mapping the dataset of (ri+ci, ri-ci) to visualize the complex interrelationships and provide information to judge which are the most important factors and how influences affected factors which provides valuable insight for making decisions. For doing that it is advisable to define a threshold value for the influence effects to filter out negligible effects. Only the effects greater than given threshold value would be shown in the graph.

\section{Research Methods}

This study presents not only evaluating possible critical success factors (CSFs) influencing organizational authority decision to adopt e-learning facilities in the level of primary education system (PES) but also cause and effect relationship among the dimensions and criteria under each dimension. Hence, evaluation of critical success factors (CSFs) influencing organizational authority decision to adopt e-learning facilities to be a tool to aid authority to define the strength and weakness in term of e-learning platform in the educational institutions. Based on the existing literature review, theoretical background and previous noteworthy empirical research findings this study developed research flowchart for DEMATEL method. The extensive literature review was conducted to identify variables and dimension of possible critical success 
factors (CSFs) for e-learning facilities more specifically in the level of primary education institutions. Based on the reviews four dimensions and fifteen evaluation criteria (sub-factor) were extracted.

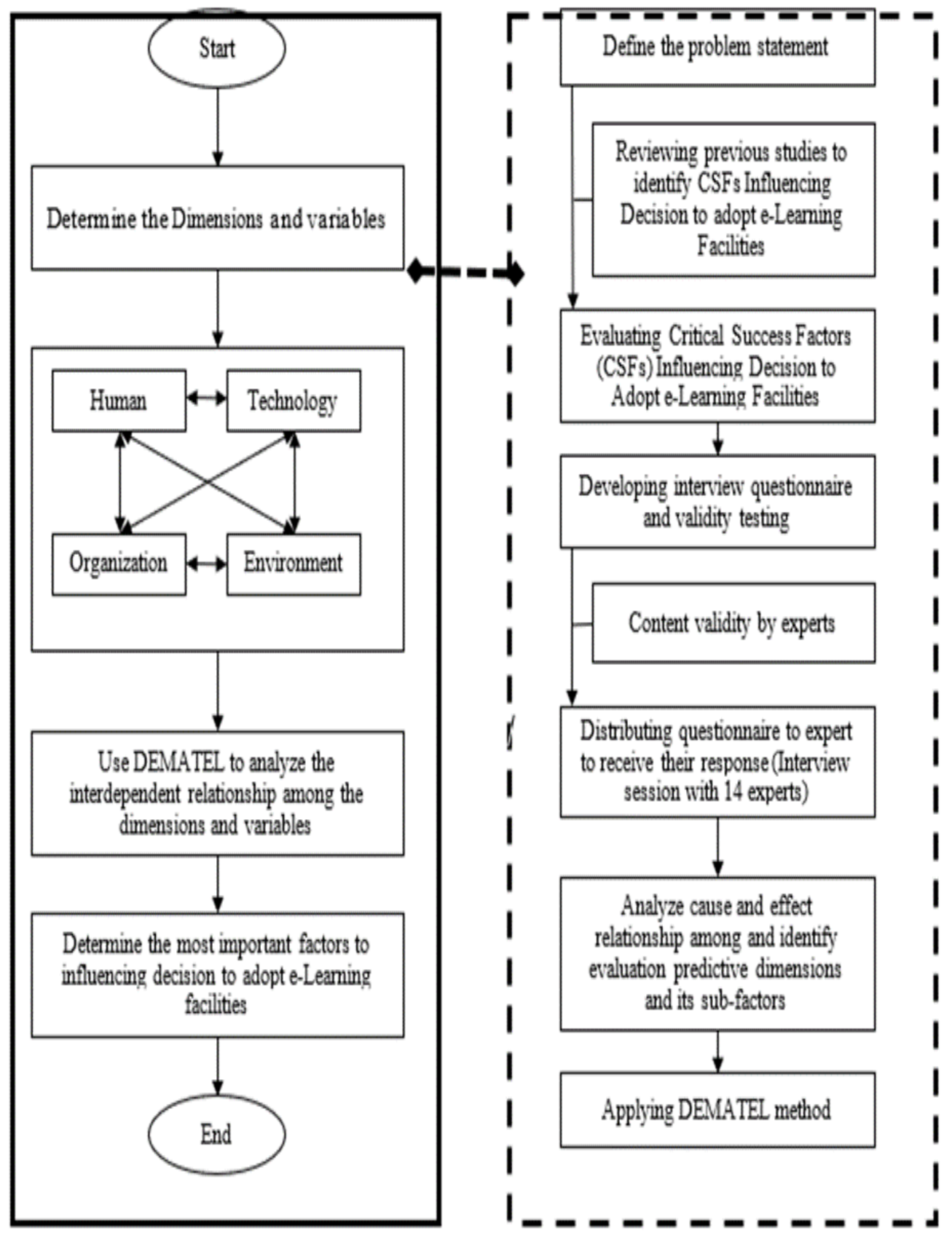

Fig. 2. Research flow chart along with process of DEMATEL method.

\subsection{Design a Questionnaire for Collecting Responses from Expert}

After obtaining the fifteen variables and four dimensions of e-learning factors adoption from literatures and a Structured questionnaire was designed. In this study, the questionnaire involved pairwise comparison of elements on a five-point scale ranging from 0 to 4 respectively $(0=$ No influence, $1=$ Low influence, $2=$ Medium influence 3 = High influence $4=$ Very High influence). DEMATEL is not statically based methodology and small sample size is enough to implement a decision. A group of qualified experts reviewed and tested the designed questionnaire to assure the content validity of questionnaire. The group of qualified experts was consisted of four education service professionals from academic institutions under 
the ministry of education who have more than 5 years of job experience relating to education service and 3 years from relating stakeholder specially who supply the technological instruments from the abroad. After interviewing, the questionnaire was revised based on expert aspects and their related opinion.

\subsection{Stages in Interview Session for Collecting Response from the Respondents}

In the current study, data were collected from 14 experts who are as decision makers that are wholly familiar with the education sector and experts were asked to complete the questionnaire. The experts have at least 3 years' experience and worked in management position in well-known either its top management level or middle level of management team of the organizational hierarchy. Thus, the respondents in this study are experts and not the users. Therefore, the sample size of 14 experts would be sufficient for data collection purpose and appropriate for DEMATEL model. In addition, many researchers have applied DEMATEL approach in their researches and provide such small sample size for the implementation. DEMATEL is not statically based methodology and small sample size is enough to implement a decision. After obtaining the completed questionnaires from the expert, DEMATEL analytical technique was used to determine the causal relations and to identify the significant dimensions and variables [49], [54], [55].

\subsection{Data Analysis Tools}

Data were collected within a few weeks in January, 2018. Snowball sampling was realized. Evaluations for bad or inconsistent data were realized in this study. MATLAB-2019 a, SPSS 23 and MS Excel were used for calculations.

\section{Empirical Study}

\subsection{Respondents Demographic Profile}

In this study, the primary data was collected through sets of pairwise questionnaire which delivered to the academician/ experts. Questionnaires have been sent through email by researchers as an efficient and effective instrument to collect data from the respondents. For this study, numbers of respondents were 14 $(n=14)$ experts. All experts give the feedback in the pairwise questionnaire (response rate 100\%). Table 4 provides the respondents' demographic profile. About $64.29 \%$ of expert were male and the rest, were female who was an academician and expert member of education sector. The distribution of the respondents by age, with $21.43 \%$ were less than 35 years old, from 36 to 45 were $50 \%, 46$ to 55 years $28.57 \%$. Approximately $65 \%$ per cent of respondents have taken "phd" degree from reputed university as well as different country in the world. As can be seen in the table, most of the experts have experience more than seven years seniority in the education department.

Table 4. Respondent Demographic Profile

\begin{tabular}{lccc}
\hline \multicolumn{1}{c}{$\begin{array}{c}\text { Pairwise Questionnaire } \\
\text { Items }\end{array}$} & Respondent Characteristics & Frequency & Percentage (\%) \\
\hline Gender & Male & 9.00 & 64.29 \\
\cline { 2 - 4 } & Female & 5.00 & 35.71 \\
\hline \multirow{2}{*}{ Age } & 25-35 Years & 3.00 & 21.43 \\
\cline { 2 - 4 } & 36-45 Years & 7.00 & 50.00 \\
\hline \multirow{2}{*}{ Education } & 46-55 Years & 4.00 & 28.57 \\
& Masters & 5.00 & 35.71 \\
\cline { 2 - 4 } & Phd. & 7.00 & 50.00 \\
\hline Experience & Others like (post doc) & 2.00 & 14.29 \\
\hline & 1-7 Years & 3.00 & 21.43 \\
\hline
\end{tabular}




$\begin{array}{cll}\text { 8-12 Years } & 6.00 & 42.86 \\ \text { More than } 13 & 5.00 & 35.71\end{array}$

\subsection{Procedure and Results}

Based on the four dimensions and fifteen criteria of adoption decision of e-learning process as stated above, this study further employed the DEMATEL method to indicate the complex relationship and identify the significant evaluation perspectives and criteria (Hung, 2011, Lee et al., 2009, Lee et al., 2011). In this section, the computation was divided into two parts for calculating on dimensions and criteria, respectively. The procedure of the DEMATEL method and the results of each stage were also presented as follows:

\subsubsection{Applying DEMATEL method on the four dimensions and variables}

$X^{k}$ showed the data gathered in terms of the four perspectives of expert $k$, where $X^{k}=\left[X_{i j}{ }^{k}\right.$. Step procedures of applying DEMATEL method as follows:

Step-1: The computation of the average matrix $\boldsymbol{Z}$ was constructed by using Eq. (i).

The average matrix $\boldsymbol{Z}$ for each dimension

\begin{tabular}{lllll}
\hline & $\boldsymbol{D}_{\mathbf{1}}$ & $\boldsymbol{D}_{\mathbf{2}}$ & $\boldsymbol{D}_{3}$ & $\boldsymbol{D}_{\mathbf{4}}$ \\
\hline $\boldsymbol{D}_{\mathbf{1}}$ & 0.000 & 1.571 & 2.429 & 2.429 \\
\hline $\boldsymbol{D}_{\mathbf{2}}$ & 1.929 & 0.000 & 3.071 & 2.929 \\
\hline $\boldsymbol{D}_{\mathbf{3}}$ & 1.643 & 1.000 & 0.000 & 2.000 \\
\hline $\boldsymbol{D}_{\mathbf{4}}$ & 1.571 & 1.857 & 2.857 & 0.000 \\
\hline
\end{tabular}

The average matrix $\mathrm{Z}$ for D1

\begin{tabular}{llll}
\hline & $\boldsymbol{C}_{\boldsymbol{1}}$ & $\boldsymbol{C}_{2}$ & $\boldsymbol{C}_{\boldsymbol{3}}$ \\
\hline $\boldsymbol{C}_{\boldsymbol{1}}$ & 0.000 & 2.071 & 2.286 \\
\hline $\boldsymbol{C}_{\boldsymbol{2}}$ & 2.143 & 0.000 & 2.714 \\
\hline $\boldsymbol{C}_{3}$ & 1.857 & 1.071 & 0.000 \\
\hline
\end{tabular}

The average matrix $\mathrm{Z}$ for $\mathrm{D} 2$

\begin{tabular}{lllll}
\hline & $\boldsymbol{C}_{\boldsymbol{4}}$ & $\boldsymbol{C}_{5}$ & $\boldsymbol{C}_{\boldsymbol{6}}$ & $\boldsymbol{C}_{\boldsymbol{7}}$ \\
\hline $\boldsymbol{C}_{\boldsymbol{4}}$ & 0.000 & 2.214 & 2.500 & 2.214 \\
\hline $\boldsymbol{C}_{5}$ & 2.071 & 0.000 & 2.786 & 2.786 \\
\hline $\boldsymbol{C}_{\boldsymbol{6}}$ & 1.571 & 1.214 & 0.000 & 2.000 \\
\hline $\boldsymbol{C}_{7}$ & 1.290 & 2.640 & 2.790 & 0.000 \\
\hline
\end{tabular}

The average matrix $\mathrm{Z}$ for D3

\begin{tabular}{lllllll}
\hline & $\boldsymbol{C}_{\boldsymbol{8}}$ & $\boldsymbol{C}_{\boldsymbol{9}}$ & $\boldsymbol{C}_{\boldsymbol{1 0}}$ & $\boldsymbol{C}_{\boldsymbol{1 1}}$ & $\boldsymbol{C}_{\boldsymbol{1 2}}$ & $\boldsymbol{C}_{\boldsymbol{1 3}}$ \\
\hline $\boldsymbol{C}_{\boldsymbol{8}}$ & 0.000 & 2.786 & 2.286 & 2.786 & 2.071 & 4.000 \\
\hline $\boldsymbol{C}_{\boldsymbol{8}}$ & 2.000 & 0.000 & 2.643 & 2.643 & 1.929 & 1.929 \\
\hline $\boldsymbol{C}_{\boldsymbol{1 0}}$ & 1.143 & 1.000 & 0.000 & 2.143 & 0.929 & 1.000 \\
\hline $\boldsymbol{C}_{\boldsymbol{1 1}}$ & 1.143 & 2.786 & 3.000 & 0.000 & 1.071 & 2.643 \\
\hline $\boldsymbol{C}_{\boldsymbol{1 2}}$ & 2.000 & 1.140 & 2.140 & 3.000 & 0.000 & 2.570 \\
\hline $\boldsymbol{C}_{\boldsymbol{1 3}}$ & 1.070 & 2.290 & 1.860 & 1.000 & 2.000 & 0.000 \\
\hline
\end{tabular}

The average matrix $\mathrm{Z}$ for $\mathrm{D} 4$

\begin{tabular}{lll}
\hline & $\boldsymbol{C}_{14}$ & $\boldsymbol{C}_{15}$ \\
\hline $\boldsymbol{C}_{\boldsymbol{1 4}}$ & 0.000 & 2.214 \\
\hline $\boldsymbol{C}_{15}$ & 2.210 & 0.000
\end{tabular}


Step-2: The normalized initial direct-relation matrix D was calculated by using Eq. (ii) to Eq. (iii). The normalized initial direct-relation matrix $\mathrm{D}$ for each dimension.

\begin{tabular}{lllll} 
& $\boldsymbol{D}_{\boldsymbol{1}}$ & $\boldsymbol{D}_{\boldsymbol{2}}$ & $\boldsymbol{D}_{\boldsymbol{3}}$ & $\boldsymbol{D}_{\boldsymbol{4}}$ \\
\hline $\boldsymbol{D}_{\boldsymbol{1}}$ & 0.000 & 0.198 & 0.306 & 0.306 \\
$\boldsymbol{D}_{\boldsymbol{2}}$ & 0.243 & 0.000 & 0.387 & 0.369 \\
$\boldsymbol{D}_{\boldsymbol{3}}$ & 0.207 & 0.126 & 0.000 & 0.252 \\
\hline $\boldsymbol{D}_{\boldsymbol{4}}$ & 0.198 & 0.234 & 0.360 & 0.000 \\
\hline
\end{tabular}

The normalized initial direct-relation matrix D for D1

\begin{tabular}{llll}
\hline & $\mathbf{C}_{\mathbf{1}}$ & $\mathbf{C}_{2}$ & $\mathbf{C}_{\mathbf{3}}$ \\
\hline $\mathbf{C}_{\mathbf{1}}$ & 0.000 & 0.426 & 0.471 \\
\hline $\mathbf{C}_{2}$ & 0.441 & 0.000 & 0.559 \\
\hline $\mathbf{C}_{3}$ & 0.382 & 0.221 & 0.000 \\
\hline
\end{tabular}

The normalized initial direct-relation matrix D for D2

\begin{tabular}{lllll}
\hline & $\boldsymbol{C}_{\boldsymbol{4}}$ & $\boldsymbol{C}_{5}$ & $\boldsymbol{C}_{6}$ & $\boldsymbol{C}_{\boldsymbol{7}}$ \\
\hline $\boldsymbol{C}_{\boldsymbol{4}}$ & 0.000 & 0.290 & 0.327 & 0.290 \\
\hline $\boldsymbol{C}_{5}$ & 0.271 & 0.000 & 0.364 & 0.364 \\
\hline $\boldsymbol{C}_{6}$ & 0.206 & 0.159 & 0.000 & 0.262 \\
\hline $\boldsymbol{C}_{7}$ & 0.169 & 0.345 & 0.365 & 0.000 \\
\hline
\end{tabular}

The normalized initial direct-relation matrix $\boldsymbol{D}$ for $\boldsymbol{D}_{3}$

\begin{tabular}{lllllll}
\hline & $\boldsymbol{C}_{\boldsymbol{8}}$ & $\boldsymbol{C}_{\boldsymbol{9}}$ & $\boldsymbol{C}_{\boldsymbol{1 0}}$ & $\boldsymbol{C}_{\boldsymbol{1 1}}$ & $\boldsymbol{C}_{\boldsymbol{1 2}}$ & $\boldsymbol{C}_{\boldsymbol{1 3}}$ \\
\hline $\boldsymbol{C}_{\boldsymbol{8}}$ & 0.000 & 0.200 & 0.164 & 0.200 & 0.149 & 0.287 \\
\hline $\boldsymbol{C}_{\boldsymbol{8}}$ & 0.144 & 0.000 & 0.237 & 0.237 & 0.173 & 0.173 \\
\hline $\boldsymbol{C}_{\boldsymbol{1 0}}$ & 0.082 & 0.072 & 0.000 & 0.345 & 0.149 & 0.161 \\
\hline $\boldsymbol{C}_{\boldsymbol{1 1}}$ & 0.082 & 0.250 & 0.282 & 0.000 & 0.101 & 0.248 \\
\hline $\boldsymbol{C}_{\boldsymbol{1 2}}$ & 0.179 & 0.183 & 0.154 & 0.215 & 0.000 & 0.185 \\
\hline $\boldsymbol{C}_{\boldsymbol{1 3}}$ & 0.172 & 0.215 & 0.134 & 0.072 & 0.144 & 0.000 \\
\hline
\end{tabular}

The normalized initial direct-relation matrix D for D4

\begin{tabular}{lll}
\hline & $C_{14}$ & $C_{15}$ \\
\hline$C_{14}$ & 0.000 & 1.000 \\
\hline$C_{15}$ & 0.998 & 0.000 \\
\hline
\end{tabular}

Step-3: The total relation matrix $\boldsymbol{T}$ was calculated by using Eq. (iv) as shown below.

The total relation matrix $\boldsymbol{T}$ for each dimension

\begin{tabular}{lllll}
\hline & $\mathbf{D}_{\mathbf{1}}$ & $\mathbf{D}_{\mathbf{2}}$ & $\mathbf{D}_{\mathbf{3}}$ & $\mathbf{D}_{\mathbf{4}}$ \\
\hline $\mathbf{D}_{\mathbf{1}}$ & 0.6191 & 0.7115 & 1.1495 & 1.0487 \\
\hline $\mathbf{D}_{\mathbf{2}}$ & 0.9299 & 0.6471 & 1.3692 & 1.2386 \\
\hline $\mathbf{D}_{\mathbf{3}}$ & 0.6475 & 0.5369 & 0.7042 & 0.8265 \\
\hline $\mathbf{D}_{\mathbf{4}}$ & 0.7721 & 0.7203 & 1.1627 & 0.7958 \\
\hline
\end{tabular}

The total relation matrix $\boldsymbol{T}$ for $\boldsymbol{D}_{1}$

$\begin{array}{lll}C_{1} & C_{2} & C_{3}\end{array}$




\begin{tabular}{llll}
\hline $\boldsymbol{C}_{1}$ & 1.3585 & 1.4265 & 1.9071 \\
\hline $\boldsymbol{C}_{2}$ & 1.7616 & 1.2061 & 2.0618 \\
\hline $\boldsymbol{C}_{3}$ & 1.2904 & 1.0321 & 1.1840 \\
\hline
\end{tabular}

The total relation matrix $\boldsymbol{T}$ for $\boldsymbol{D}_{2}$

\begin{tabular}{lllll}
\hline & $\boldsymbol{C}_{\boldsymbol{4}}$ & $\boldsymbol{C}_{5}$ & $\boldsymbol{C}_{\boldsymbol{6}}$ & $\boldsymbol{C}_{\boldsymbol{7}}$ \\
\hline $\boldsymbol{C}_{\boldsymbol{4}}$ & 0.9778 & 1.3683 & 1.7056 & 1.5181 \\
\hline $\boldsymbol{C}_{\boldsymbol{5}}$ & 1.2611 & 1.2294 & 1.8340 & 1.6579 \\
\hline $\boldsymbol{C}_{\boldsymbol{6}}$ & 0.8937 & 0.9923 & 1.0821 & 1.1654 \\
\hline $\boldsymbol{C}_{\boldsymbol{7}}$ & 1.0957 & 1.3633 & 1.6814 & 1.2543 \\
\hline
\end{tabular}

The total relation matrix $\boldsymbol{T}$ for $\boldsymbol{D}_{3}$

\begin{tabular}{lllllll}
\hline & $\boldsymbol{C}_{\boldsymbol{8}}$ & $\boldsymbol{C}_{\boldsymbol{9}}$ & $\boldsymbol{C}_{\boldsymbol{1 0}}$ & $\boldsymbol{C}_{\boldsymbol{1 1}}$ & $\boldsymbol{C}_{\boldsymbol{1 2}}$ & $\boldsymbol{C}_{\boldsymbol{1 3}}$ \\
\hline $\boldsymbol{C}_{\boldsymbol{8}}$ & 1.0249 & 1.5618 & 1.6122 & 1.7308 & 1.2399 & 1.7642 \\
\hline $\boldsymbol{C}_{\boldsymbol{8}}$ & 1.1173 & 1.3534 & 1.6335 & 1.7330 & 1.2279 & 1.6424 \\
\hline $\boldsymbol{C}_{\boldsymbol{1 0}}$ & 0.9269 & 1.2421 & 1.2423 & 1.5871 & 1.0523 & 1.4255 \\
\hline $\boldsymbol{C}_{\boldsymbol{1 1}}$ & 1.0549 & 1.5289 & 1.6403 & 1.5136 & 1.1586 & 1.6642 \\
\hline $\boldsymbol{C}_{\boldsymbol{1 2}}$ & 1.1072 & 1.4554 & 1.5094 & 1.6492 & 1.0363 & 1.5888 \\
\hline $\boldsymbol{C}_{\boldsymbol{1 3}}$ & 0.9530 & 1.2713 & 1.2709 & 1.3085 & 0.9997 & 1.2031
\end{tabular}

The total relation matrix $\boldsymbol{T}$ for $\boldsymbol{D}_{4}$

\begin{tabular}{lll}
\hline & $\boldsymbol{C}_{\boldsymbol{1 4}}$ & $\boldsymbol{C}_{\boldsymbol{1 5}}$ \\
\hline $\boldsymbol{C}_{\boldsymbol{1 4}}$ & 515.7959 & 516.7959 \\
\hline $\boldsymbol{C}_{\boldsymbol{1 5}}$ & 515.7959 & 515.7959 \\
\hline
\end{tabular}

Step -4: The total effects and net effects for each dimensions (Ds) and variables (Cs) The sums of rows and columns of matrix T were calculated by using Eq. (v) to Eq. (vii) as shown

The value of prominence and relation (Ds)

\begin{tabular}{|c|c|c|c|c|c|c|c|c|c|}
\hline & & $D_{1}$ & $D_{2}$ & $D_{3}$ & $D_{4}$ & $r_{i}$ & $c_{i}$ & $r_{i}+c_{i}$ & $r_{i}-c_{i}$ \\
\hline \multirow{4}{*}{ 总 } & $D_{1}$ & 0.6191 & 0.7115 & 1.1495 & 1.0487 & 3.5288 & 2.9686 & 6.4974 & 0.5602 \\
\hline & $D_{2}$ & 0.9299 & 0.6471 & 1.3692 & 1.2386 & 4.1848 & 2.6158 & 6.8006 & 1.5690 \\
\hline & $D_{3}$ & 0.6475 & 0.5369 & 0.7042 & 0.8265 & 2.7151 & 4.3856 & 7.1007 & -1.6705 \\
\hline & $D_{4}$ & 0.7721 & 0.7203 & 1.1627 & 0.7958 & 3.4509 & 3.9096 & 7.3605 & -0.4587 \\
\hline
\end{tabular}

Therefore, the threshold value $(\alpha)$ was derived from the average of elements in matrix T, which was calculated by using Eq. (vii).

$$
\alpha=13.880 / 16=0.867
$$

The value of prominence and relation for dimensions (D1)

\begin{tabular}{|c|c|c|c|c|c|c|c|c|}
\hline \multicolumn{2}{|c|}{ Variables (Cs) } & $C_{1}$ & $C_{2}$ & $C_{3}$ & $r_{i}$ & $c_{i}$ & $r_{i}+c_{i}$ & $r_{i}-c_{i}$ \\
\hline \multirow{3}{*}{ 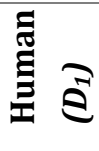 } & $C_{1}$ & 1.358 & 1.426 & 1.907 & 4.692 & 4.410 & 9.102 & 0.281 \\
\hline & $C_{2}$ & 1.761 & 1.206 & 2.061 & 5.029 & 3.664 & 8.694 & 1.364 \\
\hline & $C_{3}$ & 1.290 & 1.032 & 1.184 & 3.506 & 5.152 & 8.659 & -1.646 \\
\hline
\end{tabular}


Therefore, the threshold value $(\alpha)$ was derived from the average of elements in matrix $T$, which was calculated by using Eq. (vii).

$$
\alpha=13.228 / 9=1.470
$$

The value of prominence and relation for dimensions (D2)

\begin{tabular}{|c|c|c|c|c|c|c|c|c|c|}
\hline \multicolumn{2}{|c|}{ Variables $(C s)$} & $C_{4}$ & $C_{5}$ & $C_{6}$ & $C_{7}$ & $r_{i}$ & $c_{i}$ & $r_{i}+c_{i}$ & $r_{i}-c_{i}$ \\
\hline \multirow{4}{*}{ 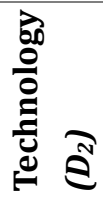 } & $C_{4}$ & 0.977 & 1.368 & 1.705 & 1.518 & 5.569 & 4.228 & 9.798 & 1.341 \\
\hline & $C_{5}$ & 1.261 & 1.229 & 1.834 & 1.657 & 5.982 & 4.953 & 10.935 & 1.029 \\
\hline & $C_{6}$ & 0.893 & 0.992 & 1.082 & 1.165 & 4.133 & 6.303 & 10.436 & -2.169 \\
\hline & $C_{7}$ & 1.095 & 1.363 & 1.681 & 1.254 & 5.394 & 5.595 & 10.990 & -0.201 \\
\hline
\end{tabular}

Therefore, the threshold value $(\alpha)$ was derived from the average of elements in matrix T, which was calculated by using Eq. (vii).

$$
\alpha=21.080 / 16=1.318
$$

\begin{tabular}{|c|c|c|c|c|c|c|c|c|c|c|c|}
\hline & & $C_{8}$ & $C_{9}$ & $C_{10}$ & $C_{11}$ & $C_{12}$ & $C_{13}$ & $r_{i}$ & $c_{i}$ & $r_{i}+c_{i}$ & $r_{i}-c_{i}$ \\
\hline \multirow{6}{*}{ 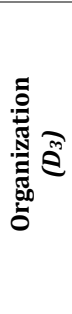 } & $C_{8}$ & 1.024 & 1.561 & 1.612 & 1.730 & 1.239 & 1.764 & 8.933 & 6.184 & 15.118 & 2.749 \\
\hline & $C_{9}$ & 1.117 & 1.353 & 1.633 & 1.733 & 1.227 & 1.642 & 8.707 & 8.412 & 17.120 & 0.294 \\
\hline & $C_{10}$ & 0.926 & 1.242 & 1.242 & 1.587 & 1.052 & 1.425 & 7.476 & 8.908 & 16.384 & -1.432 \\
\hline & $C_{11}$ & 1.054 & 1.528 & 1.640 & 1.513 & 1.158 & 1.664 & 8.560 & 9.522 & 18.082 & -0.961 \\
\hline & $C_{12}$ & 1.107 & 1.455 & 1.509 & 1.649 & 1.036 & 1.588 & 8.346 & 6.714 & 15.061 & 1.631 \\
\hline & $C_{13}$ & 0.953 & 1.271 & 1.270 & 1.308 & 0.999 & 1.203 & 7.006 & 9.288 & 16.294 & -2.281 \\
\hline
\end{tabular}

The value of prominence and relation for dimensions (D3)

Therefore, the threshold value $(\alpha)$ was derived from the average of elements in matrix T, which was calculated by using Eq. (vii).

$$
\alpha=49.031 / 36=1.362
$$

The value of prominence and relation for dimensions (D4)

\begin{tabular}{ccllllll}
\hline \multicolumn{2}{c}{ Variables (Cs) } & $\boldsymbol{C}_{14}$ & $\boldsymbol{C}_{\mathbf{1 5}}$ & $\boldsymbol{r}_{\boldsymbol{i}}$ & $\boldsymbol{c}_{\boldsymbol{i}}$ & $\boldsymbol{r}_{\boldsymbol{i}}+\boldsymbol{c}_{\boldsymbol{i}}$ & $\boldsymbol{r}_{\boldsymbol{i}}-\boldsymbol{c}_{\boldsymbol{i}}$ \\
\hline \multirow{2}{*}{$\boldsymbol{C}_{\boldsymbol{1 4}}$} & 515.7959 & 516.7959 & 1032.592 & 1031.592 & 2064.184 & 0.9998 \\
\cline { 2 - 8 } & $\boldsymbol{C}_{\boldsymbol{1 5}}$ & 515.7959 & 515.7959 & 1031.592 & 1032.592 & 2064.184 & -1.0002
\end{tabular}

Therefore, the threshold value $(\alpha)$ was derived from the average of elements in matrix T, which was calculated by using Eq. (vii).

$$
\alpha=2064.184 / 4=516.046
$$

The overall effects of the four dimensions of possible critical success factors (CSFs) influencing organizational authority decision to adopt e-learning facilities in the level of primary education system (PES) of Bangladesh.

Table 3. The Direct and Indirect Effects of Dimensions and the Direct and Indirect Effects of Variables under Each Dimension 


\begin{tabular}{|c|c|c|c|c|}
\hline & & $\left(r_{i}+c_{i}\right)$ & $\left(r_{i}-c_{i}\right)$ & REC $=$ Receiver \\
\hline \multirow{4}{*}{ 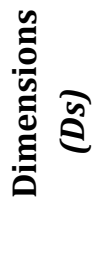 } & Human $\left(\mathbf{D}_{1}\right)$ & 6.497 & 0.560 & DIS \\
\hline & Technology $\left(\mathbf{D}_{2}\right.$ & 6.800 & 1.569 & DIS \\
\hline & Organization $\left(\mathbf{D}_{3}\right)$ & 7.100 & -1.670 & REC \\
\hline & Environment $\left(\mathrm{D}_{4}\right)$ & 7.360 & -0.458 & REC \\
\hline
\end{tabular}

The overall effects of the three variables of Human $\left(D_{1}\right)$ dimension

\begin{tabular}{cccc} 
& $\begin{array}{c}\text { Technical Competence } \\
\text { of e-learner staffs }\left(\mathbf{C}_{\mathbf{1}}\right)\end{array}$ & 0.281 & DIS \\
$\begin{array}{ccc}\text { IT Experts }\left(\mathbf{C}_{2}\right) \\
\begin{array}{c}\text { Champions } \\
\text { Innovativeness }\left(\mathbf{C}_{3}\right)\end{array}\end{array}$ & 8.694 & 1.364 & DIS \\
\cline { 3 - 5 } & 8.659 & -1.646 &
\end{tabular}

REC

The overall effects of the four variables of Technology $\left(D_{2}\right)$ dimension.

\begin{tabular}{llllll}
\hline & $\begin{array}{c}\text { Relative Advantages } \\
\left(\mathbf{C}_{4}\right)\end{array}$ & 9.798 & 1.341 & DIS & \\
\cline { 2 - 5 } & Compatibility $\left(\mathbf{C}_{5}\right)$ & 10.935 & 1.029 & DIS & \\
\cline { 2 - 5 } & Complexity $\left.\mathbf{C}_{6}\right)$ & 10.436 & -2.169 & & REC \\
\cline { 2 - 5 } & Security Concern $\left(\mathbf{C}_{7}\right)$ & 10.990 & -0.201 & REC \\
\hline
\end{tabular}

The overall effects of the six variables of Organization $\left(D_{3}\right)$ dimension

\begin{tabular}{|c|c|c|c|c|c|}
\hline \multirow{6}{*}{ 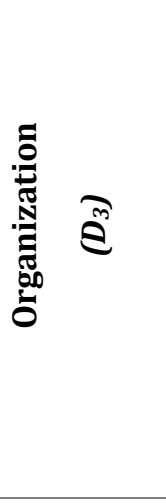 } & Centralization $\left(\mathbf{C}_{\mathbf{8}}\right)$ & 15.118 & 2.749 & DIS & \\
\hline & Formalization $\left(\mathbf{C}_{\boldsymbol{g}}\right)$ & 17.120 & 0.294 & DIS & \\
\hline & Size $\left(\mathbf{C}_{\mathbf{1 0}}\right)$ & 16.384 & -1.432 & & REC \\
\hline & Infrastructure $\left(\mathbf{C}_{11}\right)$ & 18.082 & -0.961 & & REC \\
\hline & $\begin{array}{l}\text { Top Management } \\
\text { Support }\left(\mathbf{C}_{12}\right)\end{array}$ & 15.061 & 1.631 & DIS & \\
\hline & $\begin{array}{l}\text { Financial Resources } \\
\qquad\left(\mathrm{C}_{13}\right)\end{array}$ & 16.294 & -2.281 & & REC \\
\hline \multicolumn{6}{|c|}{ The overall effects of the two variables of Environment $\left(\mathrm{D}_{4}\right)$ dimension } \\
\hline \multirow{2}{*}{ 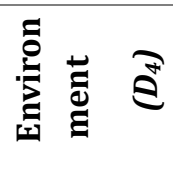 } & $\begin{array}{l}\text { Technical Competence } \\
\text { of staffs }\left(\mathbf{C}_{\mathbf{1 4}}\right)\end{array}$ & 2064.184 & 0.9998 & DIS & \\
\hline & IT Staff Experts $\left(\mathbf{C}_{15}\right)$ & 2064.184 & -1.0002 & & REC \\
\hline
\end{tabular}

Step-5: The construction of the cause and effect relationship diagram

The values of tij in Table 3, which were greater than threshold value $(\alpha)$ which presented the interaction among dimensions, e.g. the value of $t i j>\alpha$. The cause and effect diagram of four dimensions was constructed as Fig. 3.

Under each dimension, the significant variables were determined by using the same procedures. Both direct and indirect effects of the variables under four dimensions were summarized in Table- 3 and the cause and effect diagrams among criteria under each dimension were shown in Figure-4 to Figure-7. 


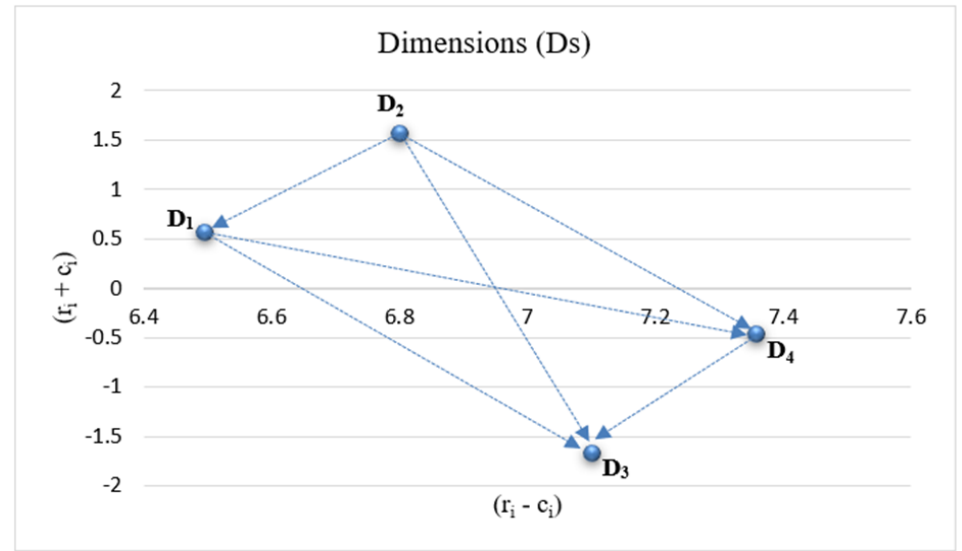

Fig. 3. The visualization of the causal relationship among dimensions of possible critical success factors (CSFs) influencing organizational authority decision to adopt e-learning facilities.

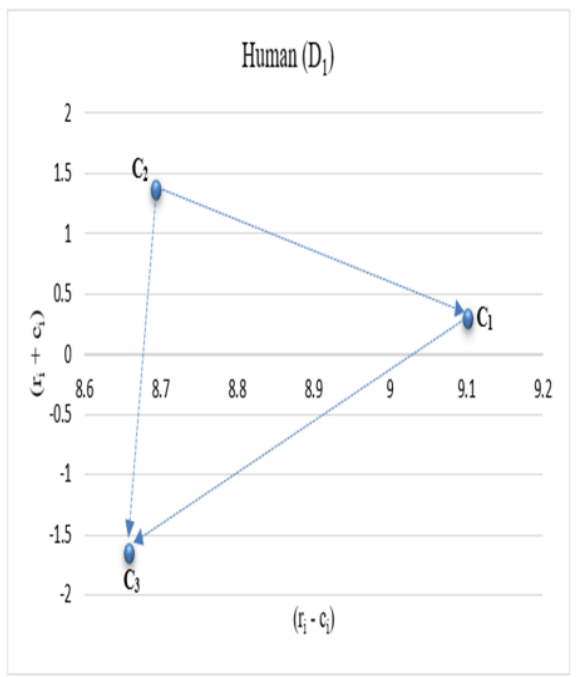

Fig. 4. The visualization of the cause and effect diagram of the three variables of human (D1) dimension.

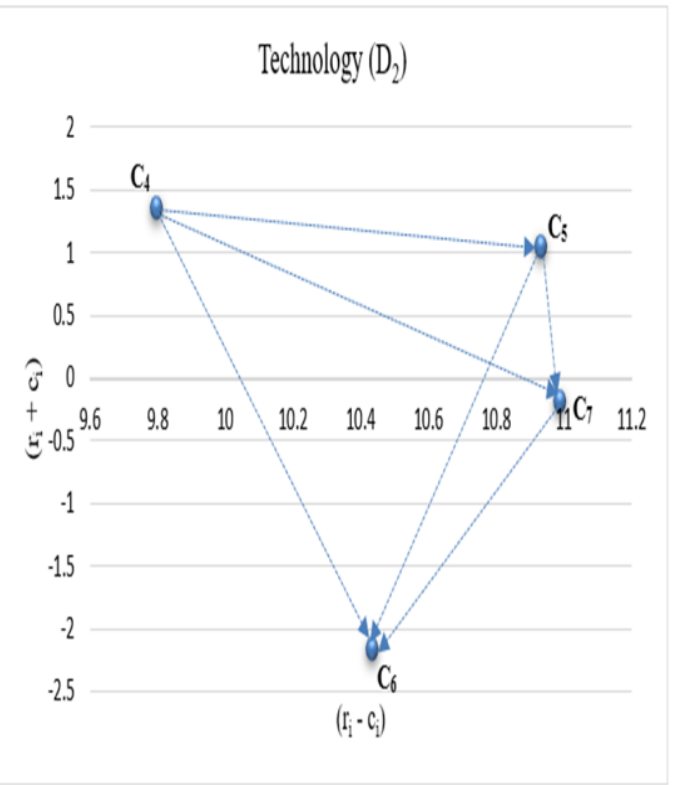

Fig. 5. The visualization of the cause and effect diagram of the four variables of Technology (D2) dimension. 


\subsection{Results on Dimensions and Criteria}

In the first part of the survey, 14 experts were asked to indicate the level to which they believe that any of the factors (dimensions and variables) influences each other in the context of influencing decision to adopt e-learning facilities by applying the scales between 0 and 4 . The direct relation/influence matrix $\mathrm{D}$ was calculated according to Eq. (i). In addition to determine the relationship among dimensions and criteria, the other contribution of DEMATEL method is to draw the impact-direction map to show the causal relation among "dispatchers" and "receivers" [21], [22], [58], [59]. To draw the impact-direction map, the sum of rows and the sum of columns in total-relation matrix $\mathrm{T}$ are respectively denoted as vector $\mathrm{r}$ and vector $\mathrm{c}$ through. The vector $r$ indicates the level of influence to others. The vector $c$, in contrast, reveals the level of relationship with others. The values of $(r+c)$ named "prominence", show the importance of factors. Similarly, the values of $(r-c)$, named "relation", divide factors into dispatchers and receivers [57]. Factors having positive values of $(r-c)$ have greater influence on one another and are assumed to have higher priority and are named dispatcher; others with negative values of $(r-c)$ receiving more influence from another are assumed to have lower priority and are called receiver. On the other hand, the value of $(\mathrm{r}+\mathrm{c})$ indicates the degree of relation between each factor with others, and factors with more values of $(r+c)$ have more relationship with another [22], [24], [48], [57]. Those having little values of $(r+c)$ have less relationship with others [23], [53], [60]. The values of prominence and relation in the matrices T of Human, Technology, Organization and environmental dimensions are similarly derived by using Eqs. (v) \& (vi) and shown in Table-3 as well. The impact-direction map of the four main dimensions is shown in Fig.-3.

\subsubsection{Results on the dimensions}

The importance of evaluating dimensions was determined by $(r+c)$ values. The technology dimension (D2) was the most important dimension with the largest $(\mathrm{r}+\mathrm{c})$ value $=6.8006$, whereas organizational context (D3) was the least important perspective with the smallest $(\mathrm{r}+\mathrm{c})$ value $=-1.6705$. Regarding to $(\mathrm{r}+\mathrm{c})$ values, the prioritization of the importance of four evaluation perspective was D2 > D1> D4> D3. Based on ( $r-c)$ values, the four perspectives were divided into (i) cause group and (ii) effect group. If the value of (r-c) was positive or net cause, such dimensions was classified in the cause group, and directly affected the others dimensions.

The highest ( $\mathrm{r}-\mathrm{c}$ ) factors also had the greatest direct impact on the others. In this study, human (D1), and technology (D2) were classified in the cause group, having the (r-c) values of 0.0.5602, and 1.5690, respectively. If the value of $(r-c)$ was negative or net receive, such dimensions was classified in the effect group, and largely influenced by the others. For this study, organization (D3), and environment (D4) were categorized in the effect group, with the $(\mathrm{r}-\mathrm{c})$ values of -1.6705 and -0.4587 respectively. And D3 was affected by the other factors (D2), (D1), and (D4).

\subsubsection{Results on the criteria}

Using the same procedure, the impact-direction maps of criteria within the dimensions of human, technology, organization, and environment are also shown in Fig. 3-7. According to human dimension (D1), this study found that IT Experts (C2) and Technical Competence of e-learner staffs (C1) were the two most important criteria based on first and second highest $(\mathrm{r}+\mathrm{c})$ values of 8.6942 and 9.1026, respectively. Whereas both IT Experts (C2) and Technical Competence of e-learner staffs (C1) were in the master dispatcher and dispatcher based on their positive ( $\mathrm{r}-\mathrm{c}$ ) values. For Champions Innovativeness (C3) was defined as receiver, given negative ( $\mathrm{r}-\mathrm{c}$ ) values of -1.6464. It can be seen that in the Human, "C2"with the highest value of $r-c$ (1.3648) is prior to others. The results indicated that, IT Experts (C2) was the most critical criteria because it directly influenced on Technical Competence of e-learner staffs (C1), and Champions Innovativeness (C3) criteria in achieving a success in e-learning facility in primary education system. This means that the effects of the other variables will achieve the goal through considering this 
factor.

In the impact- direction map of technology (D2), Relative Advantages (C4), and Compatibility (C5) are defined as dispatchers to enhance the technological benefit. Similarly, the Complexity C6), and Security Concern (C7) are regard as receiver in the impact direction map of (D2). In addition, it can be seen that in the Technology, "C4" with the highest value of (r-c) is prior to others, and is called the master dispatcher. From Figure-5, for the technology dimension, Relative Advantages (C4) presented as the most significant criteria given impact to the other three criteria.

According to organization dimension (D3), Centralization (C8), Formalization (C9), and Top Management Support (C12) are defined as dispatchers. However, Size (C10), Infrastructure (C11), and Financial Resources (C13) are regard as receiver in the impact direction map of (D3). As shown in Figure-6, Centralization (C8) had the greatest (r-c) value of 2.7496, which directly affected Formalization (C9), Size (C10), and Infrastructure (C11), Top Management Support (C12), and Financial Resources (C13) criteria. For the Organization, "C8" and "C12" can be master dispatcher with r-c (2.7496) and r-c (1.6316), respectively.

Moreover, it can be seen that in the perspective of organization (D4), there were the same importance level of the two criteria i.e. Technical Competence of staffs (C14) and IT Experts staff (C15) based on their equal $(\mathrm{r}+\mathrm{c}$ ) values of 2064.184. However, as Figure-7, IT Experts staff (C15) was a net cause having the (r-c) value of 1.0 and affected Technical Competence of staffs (C14). Also, in the organization, "C14" is master dispatcher in the impact direction map. Finally, the impact direction map of DEMATEL method facilitates decision maker to realize the causal relationship among the four dimensions in order to improve the value of technological field. Likewise, organizational authority is able to ensure quality education in the root level by choosing an adopting new technology like e-learning facility in the classroom.

\section{Conclusion}

This study proposed an approach for the strategic planning of e-learning facilities within the primary education system based on effective group decision making from the perspective of human, technology, organization, and environmental dimensions' processes. Moreover, this study applied DEMATEL method not only to analyze the four dimensions and fifteen criteria for decision to adopt e-learning facilities but also to describe the cause and effect relationship among them. The result implied that the organizational authority should concentrate on two dimensions in the cause group i.e. human and technology context. The two remaining dimensions were found in the effect group i.e. organization, and environment which were also affected by the ones in the cause group. By the aspect of prioritizing the importance of the criteria and the cause and effect relationship among criteria under two core dimensions, this study found that technical competence of e-learner staffs, IT experts, Relative Advantages, and compatibility were the most critical criteria. However, in order to ensure the quality education in the primary level, the government should allocate more resources under budget of education sector based on these core dimensions. The author recommends to the policy makers to incorporate e-learning facilities in the primary education institutes based on the principles of e-learning systems under the access to information (A2I) national project.

In this study, some implications and limitations exist which needs to be focused and scrutinized in the further studies. First there were a small number of experts in fulfilling the survey for this study. Due to the nature of the sampling method with voluntary participation, the results may be affected by self-selection bias despite the relative heterogeneity of the sample from different expert group with different instructors.

This research suggests further studies in order to extend the scope of this study. For example, additional possible success factors could be explored and incorporated in future studies. In addition, evaluating possible critical success factor influencing organizational authority decision to adopt e-learning facilities 
could be applied other multi criteria decision making such as TOPSIS, MABAC, VIKOR, and MAIRCA to obtain more representative results in the education field.

\section{Conflict of Interest}

The authors declared no potential conflicts of interest with respect to the research and/or publication of this article.

\section{Author Contributions}

All authors made substantial contributions to conception and design of the study, conducted data collection and analysis, and interpretation of data and participated in drafting the article and revising it critically for important intellectual content. All authors contributed to the revision of the manuscript and reviewed the study design and interpretation of study findings, drafted the final version submitted.

\section{Acknowledgment}

The authors would like to acknowledge Dr. Wei Huang for his valuable opinion to carry out this work.

\section{References}

[1] ADB, Asian Development Outlook 2018. (2018). ADB, Manila. Retrieved from the website: http://www.adb.org/Documents/Books/ADO/2010/ado2010.pdf

[2] GOB, Government of Bangladesh. Election Manifesto: "Vision 2021", Bangladesh.

[3] WB, World Development Indicators Online. (2018). World Bank 2018.

[4] BBI, Board of Investment, People's Republic of Bangladesh.

[5] MOE. (2018). Ministry of Education, Bangladesh. Retrieved from the website: http://www.moedu.gov.bd/index.php

[6] Bhuiyan, T. (2010). Exploring the challenges of e-learning adoption in developing countries. Proceedings of International Conference on Education and New Learning Technologies.

[7] UNESCO, ICT in Education Programme. (2006). ICT as a Tool for Achieving Literacy for All-Using ICT to Develop Literacy. Dhaka, Bangladesh.

[8] O'neill, K., Singh, G., \& O'donoghue, J. (2004). Implementing eLearning programmes for higher education: A review of the literature. Journal of Information Technology Education: Research, 3(1), 313-323.

[9] Dietinger, T. (2003). Aspects of e-learning environments.

[10] Buren, M., \& Sloman, M. (2003). E-learning's learning curve: Will they come; will they learn. in American Society for Training and Development International Conference and Exposition.

[11] Garrison, D. R. (2011). E-Learning in the 21st Century: A Framework for Research and Practice. Routledge.

[12] Britain, G. (2013). Children and parents: Media use and attitudes report. Ofcom.

[13] Goh, W. W., Bay, S., \& Chen, V. H.-H. (2015). Young school children's use of digital devices and parental rules. Telematics and Informatics, 32(4), 787-795.

[14] Hubalovsky, S., Hubalovska, M., \& Musilek, M. (2019). Assessment of the influence of adaptive e-learning on learning effectiveness of primary school pupils. Computers in Human Behavior, 92, 691-705.

[15] Hemsley, C., (2002). Jones International University's focus on quality eLearning opens doors for students worldwide. Business Media, 39(9), 26-29.

[16] NCCA, Information and communication technology (ICT) in the primary school Curriculum: Guidelines 
for teachers. Dublin: NCCA.

[17] Zounek, J., \& Šed'ová, K. (2009). Teachers and technology. Between a traditional and a modern approach. Brno: Paido.

[18] Alstrup, S., \& Rootzén. H. (2016). Possibilities and barriers for e-learning in primary school in Denmark. Proceedings of 15th European Conference on e-LearningEuropean Conference on e-Learning.

[19] Hrtoňová, N., et al. (2015). Factors influencing acceptance of e-learning by teachers in the Czech Republic. Computers in Human Behavior, 51, 873-879.

[20] Pynoo, B., et al. (2011). Predicting secondary school teachers' acceptance and use of a digital learning environment: A cross-sectional study. Computers in Human Behavior, 27(1), 568-575.

[21] Büyüközkan, G., \& Çifçi, G. (2012). A novel hybrid MCDM approach based on fuzzy DEMATEL, fuzzy ANP and fuzzy TOPSIS to evaluate green suppliers. Expert Systems with Applications, 39(3), 3000-3011.

[22] Tzeng, G.-H., Chiang, C.-H., \& Li, C.-W. (2007). Evaluating intertwined effects in e-learning programs: A novel hybrid MCDM model based on factor analysis and DEMATEL. Expert Systems with Applications, 32(4), 1028-1044.

[23] Lee, W.-S., et al. (2011). Analysis of decision-making factors for equity investment by DEMATEL and analytic network process. Expert Systems with Applications, 38(7), 8375-8383.

[24] Tsai, W.-H., \& Chou, W.-C. (2009). Selecting management systems for sustainable development in SMEs: A novel hybrid model based on DEMATEL, ANP, and ZOGP. Expert Systems with Applications, 36(2), 1444-1458.

[25] Tornatzky, L. G., Fleischer, M., \& Chakrabarti, A. The processes of technological innovation. Issues in organization and management series. Lexington Books.

[26] Tornatzky, L. G., \& Klein, K. J. Innovation characteristics and innovation adoption-implementation: A meta-analysis of findings. IEEE Transactions on Engineering Management, 1982(1), 28-45.

[27] Yusof, M. M., et al. (2008). Investigating evaluation frameworks for health information systems. International Journal of Medical Informatics, 77(6),377-385.

[28] Yap, C. S. (1990). Distinguishing characteristics of organizations using computers. Information \& Management, 18(2), 97-107.

[29] Soliman, K. S., \& Janz, B. D. (2004). An exploratory study to identify the critical factors affecting the decision to establish Internet-based interorganizational information systems. Information \& Management, 41(6), 697-706.

[30] Agarwal, R., \& Prasad, J. (1998). A conceptual and operational definition of personal innovativeness in the domain of information technology. Information Systems Research, 9(2), 204-215.

[31] Chang, I.-C., et al. (2007). Factors affecting the adoption of electronic signature: Executives' perspective of hospital information department. Decision Support Systems, 44(1), 350-359.

[32] Rogers, M. E. (1983). Diffusion of Innovations. The Free Press.

[33] Ratnasingham, P. (1997). EDI security: A model of EDI risks and associated controls. Information Management \& Computer Security, 5(2), 63-71.

[34] Grover, V. (1993). An empirically derived model for the adoption of customer-based interorganizational systems. Decision Sciences, 24(3), 603-640.

[35] Zmud, R. W. (1982). Diffusion of modern software practices: influence of centralization and formalization. Management Science, 28(12), 1421-1431.

[36] Ahmadi, H., et al. (2014). Ranking the macro-level critical success factors of electronic medical record adoption using fuzzy AHP method. International Journal of Innovation and Scientific Research, 8(1), $35-42$.

[37] Lian, J.-W., Yen, D. C., \& Wang, Y.-T. (2014). An exploratory study to understand the critical factors 
affecting the decision to adopt cloud computing in Taiwan hospital. International Journal of Information Management, 34(1), 28-36.

[38] Greenhalgh, T., et al. (2004). Diffusion of innovations in service organizations: systematic review and recommendations. The Milbank Quarterly, 82(4), 581-629.

[39] Hsiao, S.-J., et al. (2009). Critical factors for the adoption of mobile nursing information systems in Taiwan: the nursing department administrators' perspective. Journal of Medical Systems, 33(5), 369.

[40] Rogers, E. M. (2010). Diffusion of Innovations. Simon and Schuster.

[41] Haleh, H., \& Hamidi, A. (2011). A fuzzy MCDM model for allocating orders to suppliers in a supply chain under uncertainty over a multi-period time horizon. Expert Systems with Applications, 38(8), 9076-9083.

[42] Hu, S.-K., Lu, M.-T., \& Tzeng, G.-H. (2014). Exploring smart phone improvements based on a hybrid MCDM model. Expert Systems with Applications, 41(9), 4401-4413.

[43] Lee, W.-S., et al. (2009). Combined MCDM techniques for exploring stock selection based on Gordon model. Expert Systems with Applications, 36(3), 6421-6430.

[44] Qin, X.-S., et al. (2008). A MCDM-based expert system for climate-change impact assessment and adaptation planning - A case study for the Georgia Basin, Canada. Expert Systems with Applications, 34(3), 2164-2179.

[45] Rabbani, A., et al. (2014). Proposing a new integrated model based on sustainability balanced scorecard (SBSC) and MCDM approaches by using linguistic variables for the performance evaluation of oil producing companies. Expert Systems with Applications, 41(16), 7316-7327.

[46] Tsai, W.-H., et al. (2010). A MCDM approach for sourcing strategy mix decision in IT projects. Expert Systems with Applications, 37(5), 3870-3886.

[47] Wu, H.-Y., Tzeng, G.-H., \& Chen, Y.-H. (2009). A fuzzy MCDM approach for evaluating banking performance based on Balanced Scorecard. Expert Systems with Applications, 36(6), 10135-10147.

[48] Shen, Y.-C., Lin, G. T., \& Tzeng, G.-H. (2011). Combined DEMATEL techniques with novel MCDM for the organic light emitting diode technology selection. Expert Systems with Applications, 38(3), 1468-1481.

[49] Wu, W.-W., \& Lee, Y.-T. (2007). Developing global managers' competencies using the fuzzy DEMATEL method. Expert Systems with Applications, 32(2), 499-507.

[50] Ho, W.-R. J., et al. (2011). Combined DEMATEL technique with a novel MCDM model for exploring portfolio selection based on CAPM. Expert Systems with Applications, 38(1), 16-25

[51] Hung, S.-J. (2011). Activity-based divergent supply chain planning for competitive advantage in the risky global environment: A DEMATEL-ANP fuzzy goal programming approach. Expert Systems with Applications, 38(8), 9053-9062.

[52] Gabus, A., \& Fontela, E. (1973). Perceptions of the world problematique: Communication procedure, communicating with those bearing collective responsibility.

[53] Lin, C.-L., \& Tzeng, G.-H. (2009). A value-created system of science (technology) park by using DEMATEL. Expert Systems with Applications, 36(6), 9683-9697.

[54] Wang, W.-C., et al. (2012). DEMATEL-based model to improve the performance in a matrix organization. Expert Systems with Applications, 39(5), 4978-4986.

[55] Yang, J. L., \& Tzeng, G.-H. (2011). An integrated MCDM technique combined with DEMATEL for a novel cluster-weighted with ANP method. Expert Systems with Applications, 38(3), 1417-1424.

[56] Chiu, Y.-J., et al. (2006). Marketing strategy based on customer behaviour for the LCD-TV. International Journal of Management and Decision Making, 7(2-3), 143-165.

[57] Wu, W.-W. (2008). Choosing knowledge management strategies by using a combined ANP and DEMATEL approach. Expert Systems with Applications, 35(3), 828-835. 
[58] BaykasoğLu, A., et al. (2013). Integrating fuzzy DEMATEL and fuzzy hierarchical TOPSIS methods for truck selection. Expert Systems with Applications, 40(3), 899-907.

[59] Chen, J.-K., \& Chen, I.-S. (2010). Using a novel conjunctive MCDM approach based on DEMATEL, fuzzy ANP, and TOPSIS as an innovation support system for Taiwanese higher education. Expert Systems with Applications, 37(3), 1981-1990.

[60] Seyed-Hosseini, S. M., Safaei, N., \& Asgharpour, M. (2006). Reprioritization of failures in a system failure mode and effects analysis by decision making trial and evaluation laboratory technique. Reliability Engineering \& System Safety, 91(8), 872-881.

Copyright (C) 2020 by the authors. This is an open access article distributed under the Creative Commons Attribution License which permits unrestricted use, distribution, and reproduction in any medium, provided the original work is properly cited (CC BY 4.0).

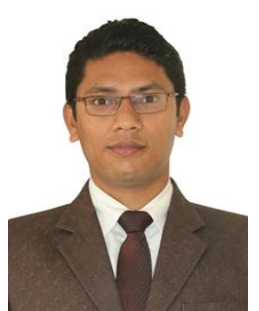

Gazi Md. Shakhawat Hossain is a candidate for master of business administration (MBA), major in management science and engineering (MSE), School of Management (SoM) at Huazhong University of Science and Technology (HUST), Hubei, Wuhan, P.R. China.

He obtained the bachelor of business administration (BBA) degree from the program of management studies, University of Barishal, Bangladesh. He was faculty first at BBA Faculty in this university. His research interest includes human resources management (HRM), corporate social responsibility (CSR), information system (IS) innovation, small and medium enterprise (SME), e-government, and work-life balance (WLB). He has published papers in journals such as European Journal of Business and Management, North American Academic Research, International Journal of Science and Business and International Journal of Innovative Research.

Wei Huang is an associate professor in the Department of Management Science and Information Management, School of Management (SoM), Huazhong University of Science and Technology, Hubei, Wuhan, 430074, P.R. China. He obtained the Ph.D. at majored in data mining and knowledge management, Japan Advanced Institute of Science and Technology, 2005. His research interest includes data mining, and risk management, etc. He has published papers in journals such as Information Fusion, International Journal of Information Technology and Decision Making, Information Sciences, Computers \& Operations Research, and Intelligent Data Analysis.

Md. Abdul Kaium is an assistant professor in the Department of Marketing at Faculty of Business Studies, University of Barishal, Barishal-8200, Bangladesh. He holds BBA \& MBA degree in Marketing. His research focuses on 'Consumer Behavior' 'Technology Adoption Behavior', 'Post-adoption Behavior' and 'Post-adoption behavior in eService sector' etc. He has published number of research articles in peer-reviewed academic national and international journals. Now he is doing Ph.D. under School of Management at Huazhong University of Science and Technology, Wuhan, China. 